\title{
Uma ficção biológico-conservadora Discursos de ódio contra as dissidências sexuais e de gênero e seus impactos na educação
}

\author{
A biological-conservative fiction \\ Speeches of hate against sexual and gender dissidences and their impact on \\ education
}

\section{Una ficción biológica-conservadora}

Discursos de odio contra las disidencias sexuales y de género y sus impactos en la educación

\section{TAMIRES TOLOMEOTTI PEREIRA*}

Universidade Federal do Paraná- Curitiba- PR, Brasil.

JAMIL CABRAL SIERRA*

Universidade Federal do Paraná- Curitiba- PR, Brasil.

\begin{abstract}
RESUMO: A partir dos estudos de gênero de vertente pós-estruturalista, investigamos um conjunto de enunciados extraídos de artigos científico-biológicos, além de um conjunto de enunciados obtidos a partir de perfis do Twitter reconhecidos por seu posicionamento odioso em relação às experiências sexuais e de gêneros dissidentes, para discutir como os estudos científico-biológicos sobre experiências trans e manifestações do desejo não heterossexuais podem ser pensados como fontes de reverberação de discursos de ódio na atualidade. Nossa aposta é que esses discursos têm sido apropriados pelo ultraconservadorismo, especialmente o de cunho religioso, como mote para a assimetria de direitos, de proteção e exposição à violência, atuando,
\end{abstract}

* Graduada em Ciências Biológicas pela Universidade Estadual de Maringá e Mestra em Educação pela Universidade Federal do Paraná, mesma instituição na qual atualmenteé Doutoranda em Educação. É membro do Grupo Interdisciplinar em Linguagem, Diferença e Subjetivação (GILDA). E-mail:<tamirestolomeotti@outlook.com>.

* Licenciado em Letras pela Universidade Estadual do Oeste do Paraná, Mestre em Letras pela Universidade Estadual de Maringá e Doutor em Educação pela Universidade Federal do Paraná. Atualmente é professor adjunto da Universidade Federal do Paraná e coordenador Grupo Interdisciplinar em Linguagem, Diferença e Subjetivação (GILDA). E-mail: <jamilcasi@gmail.com>. 
inclusive, na distribuição da precariedade a que os sujeitos da diversidade sexual e de gênero estão submetidos.

Palavras-chave: Biologia. Ultraconservadorismo. Dissidências de gênero e sexualidade. Discursos de ódio.

ABSTRACT: We have investigated a set of statements extracted from scientific-biological articles from poststructuralist gender studies. Besides investigating a set of statements obtained from Twitter profiles recognized for their odious positions in relation to sexual and gender dissident experiences. As to discuss how scientific-biological studies on transgender experiences and non-heterosexual desire manifestations can be thought of as sources of reverberation of hate-speech today. Our best bet is that these speeches have been appropriated by ultraconservatism, especially that of a religious nature, as a motto for the asymmetry of rights, protection, and exposure to violence; and even acting in the distribution of the precariousness which individuals of sexual diversity and gender are subjected to.

Keywords: Biology. Ultraconservatism. Sexual and gender dissidences. Hate-speech.

RESUMEN: Con base en estudios de género postestructuralistas, investigamos un conjunto de enunciaciones extraídas de artículos científico-biológicos, además de un conjunto de enunciaciones obtenidas de perfiles de Twitter reconocidos por su odiosa posición en relación con las experiencias sexuales y de géneros disidentes, para discutir cómo los estudios científico-biológicos sobre experiencias trans y manifestaciones de deseo no heterosexuales pueden considerarse hoy en día como fuentes de reverberación de discursos de odio. Pensamos que estos discursos han sido apropiados por el ultraconservadurismo, especialmente el de naturaleza religiosa, como un lema para la asimetría de los derechos, la protección y la exposición a la violencia, incluso actuando en la distribución de la precariedad a que los sujetos de la diversidad sexual y de género están sujetos.

Palabras clave: Biología. Ultraconservadurismo. Disidencias de género y sexualidad. Discursos de odio. 


\section{Introdução ${ }^{1}$}

$\mathrm{N}$ a disputa pelo controle dos corpos e subjetividades dos sujeitos da diversidade sexual, nos últimos anos vivenciamos uma série de tensões na arena política entre movimentos LGBT e grupos ultraconservadores, em especial, os de cunho religioso. Ao menos desde 2011, com o veto ao projeto "Escola sem homofobia", as investidas conservadoras têm se tornado mais truculentas, incluindo, além de uma "educação sem gênero", uma série de violações contra a liberdade de cátedra, as produções acadêmicas voltadas aos estudos de gênero e sexualidade, as exposições e manifestações artísticas de gêneros e sexualidades dissidentes, e as estratégias de combate à violência e discriminação sexual e de gênero. De fato, as polêmicas suscitadas pelos arautos da moral e dos bons costumes já não são novidade, mas se repetem ad nauseam, agora, reforçadas por (ao mesmo tempo que também reforçam) manifestações antidemocracia, por uma rede de fabricação de fake news, e pela disseminação de discursos de ódio.

Nesse contexto, argumentamos que as mídias sociais se tornaram espaços privilegiados para a produção e circulação de enunciados que, performativamente, atuam aprofundando a precariedade a que estão submetidas as minorias sexuais (BUTLER, 1997; 2018). Como efeito importante dessas operações políticas, a ressignificação de palavras como família, sexo, gênero e diversidade tem instaurado um verdadeiro policiamento epistemológico. Por isso que, nesse jogo de ressignificação, família (a legítima, a tradicional) é afeita à composição pai, mãe e prole; gênero é uma ideologia responsável pela erotização infantil e, consequentemente, pela produção de sujeitos perigosos, como os pedófilos e os ideólogos de gênero-comunistas-doutrinadores; sexo é depurado de qualquer historicidade - menina é $X X$, menino é $X Y$ (há mesmo quem diga que se trata de uma "identidade biológica"); e diversidade é reduzida a diferença anatômica-divina entre homens e mulheres e, principalmente, aquilo que deve ser resguardado de "ataques ideológicos" que visariam uniformizar um mundo, ironicamente, "sem gênero" e sem família.

É justamente a presença de enunciados científico-biológicos em proposições como essas que temos investigado. Suspeitamos que, ao aproximar as experiências sexuais e de gêneros dissidentes de noções perigosas, como doença, desvios de comportamento e signo de morte ao sujeito da norma, o ultraconservadorismo e, em especial, o de cunho religioso, tem legitimado ataques violentos contra a possibilidade de uma vida mais vivível ao que difere da cisheteronormatividade ${ }^{2}$. Deste modo, partimos de teorizações dos estudos de gênero de vertente pós-estruturalista para analisar, genealogicamente, um conjunto de enunciados disseminados via Twitter de perfis reconhecidos publicamente por seu posicionamento odioso em relação a essas experiências dissidentes, além de um conjunto de enunciados extraídos de artigos científico-biológicos sobre as bases biológicas dessas experiências ${ }^{3}$. 
Com esse gesto, não objetivamos remontar uma suposta origem dos dizeres conservadores, mas expor os problemas por eles suscitados, que estão longe de ser apenas abstrações ou demonstrações de "má fé". Em consonância com os artigos científicos selecionados, esses enunciados estão apoiados em formações discursivas não menos problemáticas, imersas em conflitos ético-políticos do próprio fazer científico, como a determinação do sexo que, por extrapolação, determina uma identidade de gênero "segura"; os efeitos binários e excludentes da divisão entre sexo e gênero; o problema epistemológico que o sexo representa, bem como seu princípio de inteligibilidade. Entendemos que esses problemas são precisamente aquilo que tem permitido a aliança entre os discursos científico-biológicos deterministas e os discursos ultraconservadores, uma vez que, além de serem discursos inteligíveis ou discursos de verdade, autorizam os conteúdos odiosos e servem à renaturalização do sistema corpo-gênero-desejo, que, arriscamos dizer, tem sido o mote para a interferência conservadora tanto nas políticas públicas voltadas ao combate à discriminação sexual e de gênero, quanto para o campo da educação, principalmente a educação para os gêneros e as sexualidades.

\section{Uma ficção biológico-conservadora}

Desde o final do século XVII, o sexo foi definido segundo um modelo binário com a ajuda de diversos campos conceituais, como a fisiologia, a anatomia, a endocrinologia e a genética. Esses campos são acionados para fundamentar a distinção entre machos e fêmeas, mas também representam obstáculos epistemológicos para a própria compreensão científica do sexo, uma vez que a determinação dos processos de sexuação em duas categorias absolutamente distintas não pode ser sustentado cientificamente (DORLIN, 2009). Panes no (cis)tema acontecem com frequência, como quando o número de cromossomos autossomos e sexuais diferem da condição 46, XX ou 46, XY; ou para aqueles nascimentos em que a genitália não pode ser claramente identificada como feminina ou masculina; ou, ainda, quando a genitália é "incompatível" com a constituição cromossômica sexual - isso para citar alguns exemplos. Anne Fausto-Sterling (1993) nos provoca a pensar que se levássemos a cabo o que supõe a biologia, no espectro entre macho e fêmea, existiriam pelo menos cinco sexos $(X X, X Y, X X X, X X Y, X Y Y)$ e, talvez, mais do que isso.

De fato, é estranho pensar que, para a sociedade ocidental, tão ciente de seus feitos científicos, o que se considera legítimo para o sexo ainda se cristalize no binômio hierarquizado masculino/feminino. Um ponto de inflexão importante sobre isso está situado na década de 1950, junto ao esforço da scientia sexualis e o engendramento da ideia de "sexo biológico" que, já naquele momento, mostraria os limites e a plasticidade do desenvolvimento sexual. Na prática, isso significou a independência do sexo em relação ao gênero, já que o sexo poderia ser manipulado quimica e cirurgicamente; no entanto, em 
que se pensava haver uma emancipação dos determinismos biológicos que justificavam as relações sociais desiguais entre homens e mulheres, paradoxalmente, o sexo foi entendido como um objeto a-histórico e natural, reduzido às categorias macho e fêmea, enquanto o gênero adquiriu um caráter essencialista, como uma inscrição cultural sobre os corpos já sexuados.

Somente no final dos anos 1980 a historicidade do sexo biológico receberia destaque nos campos da sociologia, da filosofia e da história da Ciência e o gênero se tornaria uma categoria útil de análise histórica ${ }^{4}$, um conceito crítico que colocaria em suspenso a naturalização do sexo. Nesse tensionamento, Judith Butler (2003) nos diz que se o caráter imutável do sexo é contestável, talvez ele seja tão culturalmente construído quanto o gênero. Em última instância, não há distinção entre sexo e gênero, porque o gênero não pode ser concebido como uma simples inscrição cultural em um corpo previamente sexuado, mas como o meio discursivo pelo qual um "sexo natural" é produzido e estabelecido como uma superfície politicamente neutra sobre a qual age a cultura. Dito de outro modo, dispor a dualidade do sexo em um domínio pré-discursivo é uma estratégia para assegurar a estabilidade interna e binária do sexo. Aliás, ignorando suas próprias contradições, é justo dizer que o "biológico" só interessa à medida que pode corroborar a substancialização das próprias categorias que intenta apreender, pois, independentemente das vias que tomar (ou das intervenções hormonais e cirúrgicas), o objetivo parece ser a designação de um "bom sexo", isto é, composto por um aparato genital masculino ou feminino funcional e harmônico em um comportamento sexual considerado "normal" (DORLIN, 2009).

Os materiais empíricos que selecionamos não escapam aos mesmos determinismos evocados por essa crise científica, ética e política (DORLIN, 2009; FAUSTO-STERLING, 2012). Considerando os artigos científicos, para além da diversidade de abordagens escolhidas, as bases biológicas das sexualidades e dos gêneros dissidentes são sempre justificadas em uma relação hierárquica que as supõem como desvios ou anormalidades, afinal, persistem nesses estudos uma vontade de verdade sobre o sexo que não se cansa de descobrir e reinventar seus próprios (a)objetos. De modo parecido, os enunciados conservadores que extraímos do Twitter afirmam que essas experiências devem ser tratadas terapeuticamente ou exterminadas, já que constituem anomalias da natureza e representam riscos à família tradicional, ou, ainda, à espécie humana. Optamos, então, por analisar esses dois conjuntos de materiais paralelamente, começando por excertos de três artigos científicos, além de alguns tweets:

A inversão sexual, problema sem solução que acompanha o homem, desde os tempos mais remotos, era assunto que não podia ser tratado, em público, por ser contrário aos bons costumes e à moral. Nos fins do século passado começou a questão a ser ventilada, à luz de argumentos científicos, para que a humanidade pudesse, afinal, beneficiar-se desses estudos, tentando corrigir defeitos e doenças tão tristes e tão deprimentes da natureza humana. [...] Certas causas orgânicas, como a 
encefalite, sífilis, meningite e traumatismos cranianos, podem provocar, em certos casos, o aparecimento de tendências homossexuais. [...] Ninguém poderá mais, assim, duvidar hoje de que a homossexualidade seja um fenômeno condicionado a um estado de bissexualidade do organismo, isto é, um verdadeiro "estado intersexual" (RIBEIRO, 2010: 498-503).

Pode ser que nos seres humanos os hormônios controlem a diferenciação do cérebro e a direção da subsequente escolha do objeto sexual na vida adulta. [...] o comportamento dos homens homossexuais primários tem como causa essencial um cérebro feminino diferenciado. Vemos essa diferenciação como resultado da ausência de um efeito androgênico no hipotálamo durante o período crítico para a diferenciação do sexo (MACCULLOCH, 1980: 137, tradução livre).

A partir dos achados deste estudo, parece haver uma diferença biológica definida entre o grupo HHF (homens homossexuais femininos) e todos os outros estudados, na medida em que não há uma redução usual na colinesterase sérica após a administração subcutânea de $1 \mathrm{mg}$ de prostigmina. Deve-se chamar atenção para o fato de que não é uma característica da mulher, uma vez que mulheres (presumidamente sexualmente normais) mostram a mesma magnitude de redução que os homens (WILLIAMS, 1944: 69-70, tradução livre, adição nossa).

A própria natureza mostra a diferença entre masculino e feminino, a genética também, as olimpíadas idem. Esses esquerdopatas são uma piada (tweet 1, 2016).

Ser Mulher não é apenas um Gênero. Ser mulher abarca 1.552 diferenças do sexo oposto, gênero cultural é ativismo político (sic) não é ciência (tweet 2, 2019).

CIS é ideologia de vocês, eu sou Hetero mesmo, mulher biológica com todos os estereótipos "opressores" maravilhosos de uma mulher 100\% feminina (gestante, xx, hormônio etc) felicidade (sic). Tenho meu direito de externar minha NATUREZA BIOLÓGICA (tweet 3, 2019).

[...] O ser humano foi feito para fumar? NÃO! Mas fuma. Foi feito para cheirar cocaína? NÃO! Mas cheira. Foi feito para ser Bi ou homossexual? NÃO! Mas é. PORQUE? (sic) Tem o livre arbítrio e o poder do pecado para contrariar a sua própria natureza. MACHO E FÊMEA (tweet 4, 2019).

O questionamento não é novo, mas ainda é pertinente: considerando uma base biológica específica para as sexualidades dissidentes, assim o seria para qualquer outra expressão afetivo e/ou sexual do desejo. O que as tornam passíveis de investigações e de experimentos, ao passo em que a heterossexualidade goza de seu status e parâmetro de normalidade? Em que pese os enunciados científicos forçarem a existência de uma causa para a homossexualidade, mesmo em ínfimas coisas, o que está em jogo é o reforço da naturalização da coerência sexo-gênero-desejo em rechaço às experiências ininteligíveis. O conservadorismo parece ter entendido muito bem o recado, já que o sexo biológico se tornou motivo de orgulho e de ataque à diferença, sobretudo, porque a partir daí é possível atribuir um sexo ou um gênero danificado, criando um terror aos atos sexuais e/ou afetivos dissidentes - um terror de perder a substância ou a própria natureza, que desempenha um papel fundamental na regulação do gênero e da sexualidade por meio do controle e da humilhação (BUTLER, 1993). 
Um dos casos que podem explicitar essa questão concerne à aprovação do Plano Municipal de Educação de Curitiba para o decênio 2015-2025, que, além de suprimir qualquer menção à gênero e orientação sexual, como aconteceu em outros municípios e estados, bem como com o próprio Plano Nacional de Educação, incluiu, em suas diretrizes, o inciso IX, que visa a "promoção dos princípios do respeito aos direitos humanos, à diversidade cultural e à sustentabilidade socioambiental, com direito à identidade biológica (do homem e da mulher)" (Curitiba, 2015, p.2). Eis, aqui, uma tentativa não só de barrar as discussões de gênero e sexualidade em âmbito escolar, mas de firmar os limites que investem certos corpos de legibilidade ou, ainda, de dar novos contornos ao "sujeito de direito". Com efeito, noções anátomo-fisiológicas e de reprodução foram usadas para legitimar as pautas conservadoras em outros projetos de lei, como o Estatuto da Família (PL6583/2013), o Escola sem Partido (PL867/2015), a Criminalização da Heterofobia (PL7382/2010), dentre outros, todos eles tendo a escola como um de seus principais alvos, na tentativa de impedir que os temas de gênero e sexualidade cheguem até professoras e professores, estudantes, pais, comunidade escolar. Nos parece que o que esses projetos põem em curso é a promoção da censura, começando pela escola.

Como parte desse problema, há uma tentativa de determinar quais corpos podem ocupar a posição de sujeito da homossexualidade ${ }^{5}$, conforme os próximos enunciados:

Caso 3. Um homem branco de quarenta e quatro anos de idade. Tem sido homossexual desde o início da juventude. Passou a maior parte de sua vida em instituições penais devido às oportunidades para satisfazer sua perversão. Ele parecia orgulhoso do fato de ser "homem-mulher" (OWENSBY, 1940: 65-66, tradução livre).

Os cálculos iniciais no final do teste confirmaram a impressão de que havia duas categorias de homossexuais - primária e secundária - a primeira é formada por aqueles que relataram nunca terem manifestado interesse heterossexual (MACCULLOCH, 1980: 133, tradução livre).

Os homens homossexuais masculinos (HHM) eram pós-adictos conhecidos por ter desempenhado o papel masculino com pelo menos uma pessoa do grupo HHF (homens homossexuais femininos). Não fomos capazes de obter alianças com este grupo, mas não encontramos motivos para acreditar que preferiam os homossexuais às atividades heterossexuais (SILVERMAN; ROSANOFF, 1945: 311, tradução livre).

POVO BRASILEIRO! Essa cambada de devassos, esquerdopatas, libertinos e at (ativistas) gays, SÃO A MINORIA! N (sic) podem nos impor suas imoralidades. $\tilde{N}$ (sic) se cale (tweet 5, 2017, adição nossa).

Homossexualidade ñ (sic) é pecado, mas a sua prática é! [...] conheço homossexuais q (sic) servem a Deus e fizeram o voto da castidade (tweet 6, 2012).

Essa cambada quer destruir os valores da família q(sic) tem sustentado a civilização humana até aqui. FELIZ DIA DOS PAIS! É COISA DE MACHO! (tweet 7, 2016). 
Desde a invenção da figura homossexual afeminada ao atributo biológico diferenciado, há todo um esforço para desvencilhar homens homossexuais de "homens de verdade", apelando até mesmo para noções sexistas e machistas. Se para ser elegível às pesquisas alguém deveria ser considerado "verdadeiramente homossexual", esses estudos deflagram, novamente, um modelo que define a homossexualidade como algo bidimensional e estático, de modo que essa escolha arbitrária satisfaça a própria descrição imaginária científica sobre as sexualidades e gêneros dissidentes. Nesses documentos, tanto os "homens homossexuais femininos" (homens que são penetrados por outros homens), como os "homens homossexuais cuja anomalia é facultativa" (que desempenham um papel "tipicamente masculino" na relação sexual) são caricaturas forjadas e se aproximam muito mais de um "componente da política, da sociedade, e da moral cultural e econômica do que de um fato da natureza, como pretende a grande maioria dos discursos médicos" (FAUSTO-STERLING, 2000: 5). Além disso, quanto mais os sujeitos examinados estivessem afastados dos padrões de masculinidade (no caso dos homens) ou dos padrões de feminilidade (para as mulheres), maior a abertura para outras suspeitas. Ora, nos enunciados conservadores essa lógica é suplantada por outras categorias, como "esquerdopatas", "devassos", "libertinos", "destruidores da família”, entre outras, mas produz efeitos muito semelhantes.

Maura Corcini Lopes (2009), ao tecer estudos sobre a surdez, fala em curvas de normalização que funcionam banindo para as zonas abjetas e inabitáveis os sujeitos que estão mais longe da norma. Ainda que aqui o caso não seja a surdez, o mesmo pode ser pensado, isto é, esses sujeitos estariam, nessas curvas de normalização, mais longe de um ponto que pode ser definido como masculino, cis, heterossexual, cristão etc. Mesmo entre as experiências dissidentes, tomando os tweets 5, 6 e 7 como exemplo, há uma distinção entre "homossexuais que servem a Deus" e "ativistas gays"; estes últimos são engendrados como um perigo aos sujeitos da norma, à família tradicional, às crianças e, em último caso, à espécie, conforme os tweets abaixo:

O at(ativismo) gay quer controlar os homossexuais. É uma violação das garantias individuais no estado democrático de direito (tweet 8, 2017, adição nossa).

Ditadura gay quer transformar a heterossexualidade em anormal (tweet 9, 2014).

Dá para entender minha luta contra o ativismo gay? Não é possível ser ignorante e deixar de ver a desgraça que essa gente faz (tweet 10, 2014).

Ativistas gays, devassos e esquerdopatas, estão em uma campanha internacional para dar normalidade a pedofilia. Onde chegou à humanidade (tweet 11, 2017).

OMS afirma que gays tem 19 vezes mais chance de contrair o HIV do que a população em geral (tweet 12, 2014).

$\tilde{N}($ sic) falar ñ(sic) alertar é crime! Lembra os artistas mortos pela AIDS? Qtos(sic) eram gays? A expectativa de vida dos LGBTT é 20 anos menor q(sic) dos demais (tweet 13, 2012). 
Aqui, cabe ressaltar a importância do dispositivo da aids/HIV na repatologização das sexualidades e dos gêneros dissidentes (PELÚCIO; MISKOLCI, 2009). Na década de 1980 um moralismo científico, religioso e midiático responsabilizou a homossexualidade por disseminar a aids, tanto que ela seria conhecida como a "peste gay", uma espécie de doença moral da homossexualidade. Para João Silvério Trevisan (2002), a aids foi associada à peste porque as doenças em massa são sempre significadas como castigos divinos; aliás, é como se ela não trouxesse nada de novo à tona, mas exacerbasse o ressentimento com um elemento de culpabilidade ou de punição que os homossexuais "mereciam". Esse estigma persiste nas narrativas conservadoras, servindo como motivo para a incitação de pânicos morais que alimentam e justificam investidas violentas contra essas experiências (MISKOLCI, 2007; CÉSAR; DUARTE, 2017), incluindo as terapias de "cura gay".

Se em 1973 a homossexualidade foi retirada do DSM-III (Diagnostic and Statistical Manual of Mental Disorders) e as técnicas científico-biológicas de normalização como os eletrochoques, os transplantes testiculares e as induções de convulsão com drogas entraram em relativo desuso ${ }^{6}$, por outro lado, elas abriram espaço para outros tipos de tratamentos em uma roupagem religiosa-doutrinária. Um artigo científico que selecionamos, publicado em 2003, entrevistou 200 homossexuais que teriam mudado de orientação sexual, passando a se identificar como heterossexuais, após algum tipo de terapia relacionada aos saberes psi (SPITZER, 2003). Os resultados das entrevistas podem nos ajudar a esmiuçar a questão: a maioria era cristã, sendo $81 \%$ protestantes, $8 \%$ católicos, $7 \%$ mórmons, e $3 \%$ judeus. É válido dizer que 19\% dos entrevistados eram profissionais da saúde mental ou diretores de ministérios religiosos "ex-gays". Sobre os motivos pelos quais essas pessoas desejaram mudar de orientação sexual, 79\% disseram ser pelo conflito entre seus sentimentos e comportamentos sexuais e os princípios de sua religião. Quanto ao tipo de terapia praticada, $48 \%$ disseram que a terapia era feita com psicólogos, $25 \%$ com pastores, e $5 \%$ com psiquiatras; sendo que $34 \%$ acreditam que o único tipo de terapia eficaz era realizado junto aos grupos de ex-gays e grupos religiosos, e 19\% reportaram que o único tipo de terapia eficaz incluía coisas como biblioterapia ou mudar sua relação com Deus. Sobre os principais assuntos conversados em terapia, alguns tópicos incluíam: relacionamentos familiares conturbados e experiências traumáticas na infância. Há, ainda, uma correlação entre depressão antes e após a terapia. As pessoas relataram que são muito mais felizes após a terapia (91\% dos homens e 88\% das mulheres); os homens disseram se sentir muito mais "homens" e as mulheres disseram se sentir muito mais "femininas". Por fim, a grande maioria das pessoas entrevistadas nesse estudo pertenciam a organizações religiosas que, inclusive, são fortes centros de luta contra as dissidências sexuais e de gênero nos estados unidos, como a National association for research $\mathcal{E}$ therapy of homosexuality (Narth) e a Exodus international, cujo slogan é "liberte-se da homossexualidade através do poder de jesus"7. 
No cenário brasileiro, além da apropriação de teorias psicologizantes que articulam as experiências dissidentes em torno das concepções de "vício, compulsão e transtornos mentais" (NATIVIDADE, 2006: 119), as propostas de "cura gay" também são ensaiadas às custas da falta de evidências genéticas que as expliquem, de modo que a existência de "ex-gays" seria a prova incontestável de um retorno possível e desejável à norma. A diversidade que será cada vez mais defendida pelos setores conservadores talvez seja aquela da qual falávamos há pouco, a diversidade natural e divina, que reafirma o sexo biológico e os preceitos doutrinários religiosos, conforme os tweets:

O que eu falo há muito tempo, a ciência comprova: ninguém nasce gay! (tweet 14, 2019).

Existem varias (sic) casos que a imprensa deu notícia como homofobia, depois se verificou como crime comum ou briga entre eles. Qualquer um que se sentir agredido, ofendido, (sic) já existem leis para isso. Comparar homofobia a racismo é piada. Raça é condição, gay é comportamento (tweet 15, 2019).

Ex Gays existem, são a minoria dentro de uma minoria, escondida pelo preconceito de quem diz defender a diversidade e a pluralidade. O nome disso é hipocrisia (tweet 16, 2019).

Talvez as manifestações conservadoras tenham razão em dizer que a sexualidade não é um destino genético, mas, certamente, o objetivo não é contrariar qualquer determinismo biológico. Conforme tentamos dizer, os enunciados científico-biológicos que são apropriados nos enunciados conservadores seguem a regra do "pode ser útil"; não há uma preocupação com os conteúdos ou mesmo com a coerência quando o que está em jogo é a disputa hegemônica do discurso e da vontade de verdade e poder. Nesse sentido, a polemização da "cura gay" vem acompanhada por tentativas de descreditar o Conselho Federal de Psicologia, e arrasta para o debate público questões como a liberdade de expressão e a liberdade de atuação de quem a defende. Como forma de visibilizar esses argumentos, destacamos alguns tweets:

OCONSELHO FEDERAL DE PSICOLOGIA deixou de ser um órgão de ciência para ser um instrumento do ativismo gay e de ideologia esquerdopata (tweet 17, 2017).

Opinião não é homofobia. Opinião não é crime. Os esquerdopatas, libertinos, ativistas gays, não suportam o contraditório. Estamos na democracia (tweet 18, 2015).

Pergunto ao ministro: será tolhido meu direito de pregar a palavra como ela é? Partes da Bíblia serão proibidas de serem lidas e publicadas? Se um casal gay quiser se casar numa igreja evangélica ou católica e seus sacerdotes se negarem, isso será preconceito? Seremos presos? (tweet 19, 2019).

Ao contrário do que supõem os enunciados destacados, a liberdade de expressão não pode ser, em hipótese alguma, o direito de insultar pessoas e grupos em virtude dos pertencimentos de raça, gênero, sexualidade, entre outros. Não se trata de tentar 
cercear termos, palavras ou expressões, até porque o problema não se reduz à existência de um discurso desumanizador, a questão mais pungente é a "existência de limites para o discurso que estabelecem as fronteiras da inteligibilidade humana" (BUTLER, 2006: 35). Nesse sentido, os discursos de ódio não são discursos meramente descritivos, mas podem ser entendidos como performativos, isto é, capazes de produzir efeitos que atuam, inclusive, nas normas de reconhecimento, diferenciando as vidas que são passíveis de serem vividas das que não o são (BUTLER, 1997; 2015).

Pensando no que nos é mais próximo, o policiamento epistemológico do gênero e da sexualidade seria um paradoxo, porque se aproxima da vontade de uma interpelação violenta desses sujeitos, ameaçando sua existência, ao mesmo tempo que os produzem como algo a ser expurgado. A questão se estende até mesmo a uma dimensão contagiosa (BUTLER, 1997), em que falar sobre outras formas de viver que não a cisgênero e heteronormativa é entendido como um modo de "transformar" crianças em homossexuais, ou mesmo de instaurar uma "ditadura gay" no Brasil. Ao que parece, a existência desses sujeitos, bem como suas condições de aparecimento nos espaços públicos, está sendo tomada como uma ameaça à soberania nacional, já que figurariam evidências apocalípticas da destruição da família tradicional, entendida como o sustentáculo da "pátria amada", conforme os tweets a seguir:

Temos a honra de ser chamados de conservadores. Conservamos a família, os bons costumes q(sic) trouxeram a civilização humana até aqui [...] (tweet 20, 2016).

PRECOCE. A exposição de temas como a homossexualidade a crianças é, segundo a psicóloga Marisa Lobo, um perigo que pode surtir efeitos prejudiciais à formação psíquica delas (tweet 21, 2019).

'Menino veste azul e menina veste rosa' é uma metáfora para dizer que não vamos admitir que a inocência das crianças seja violada por ideologias políticas e sexuais que erotizam e corrompem o entendimento natural das crianças sobre sexualidade (tweet 22, 2019).

Minha opinião: Não acho que é hora de abrir diálogo com movimentos sociais lgbtts. Lutamos tanto contra kit gay, ideologia de gênero, privilégios, ataques a heteronormatividade [...] (tweet 23, 2018).

Ao declarar a inconstitucionalidade de leis q(sic) proíbem ideologia de gênero no ensino fundamental, STF pode acabar levando pais a fazer justiça c/ as próprias mãos p/ defender a integridade psíquica e moral dos seus filhos e o direito sagrado de educá-los. Professores que se cuidem (tweet 24, 2020).

Os discursos de ódio conservadores insistem na codificação das minorias sexuais (BUTLER, 1997), posicionando-as como um tipo de infração contra a heteronormatividade e os valores tradicionais ou, simplesmente, como inimigos morais a serem combatidos pelos "cidadãos de bem". Essa mobilização moral do medo à diferença se propõe como um desafio às instituições de ensino e, particularmente, aos docentes, quando estudantes 
e suas famílias são convocados a vigiar e denunciar falas, posturas e posicionamentos em sala de aula enquadrados (BUTLER, 2015) como ataques à "liberdade de consciência e de crença" ${ }^{\prime \prime}$. Somam-se a isso ameaças de processos, exonerações e, em última instância, da impossibilidade de viver, como evidencia o tweet 24: "os professores que se cuidem". Estratégias como essas são bons exemplos da capilaridade dos discursos de ódio via mídias sociais, porque para além da defesa de medidas inconstitucionais, como o projeto Escola sem Partido, por exemplo, os enquadramentos produzidos por esse tipo de discurso agem como justificativas para a perseguição e retaliação.

Com efeito, a análise que fizemos até aqui sinaliza como as mídias sociais atualizam seu papel pedagógico (FISCHER, 1997), regulando o que poderá ser dito, de que modo e por quem, instituindo as corporalidades e práticas afetivas e/ou sexuais desejáveis, passíveis de reconhecimento, bem como o seu inverso, circunscrevendo, assim, um “domínio no qual o discurso político opera" (BUTLER, 2019: 15). Ainda, a mídia pode ser pensada como uma forte aliada aos saberes científico-biológicos, como uma espécie de porta-voz das biopolíticas que especificam, corrigem e normalizam, até porque pode ser facilmente alcançada e desenvolve maneiras, cada vez mais incisivas e imperceptíveis, de delimitar, conhecer e administrar os comportamentos sexuais (SIERRA, 2004; 2013). É justamente nesse espaço que os discursos de ódio se ramificam e tomam novas formas para produzir efeitos de verdade sobre os corpos, os desejos, os prazeres e as experiências dissidentes.

Esse aspecto também pode ser notado na tentativa de ressignificação de palavras como "gênero", que se torna uma ideologia comunista e LGBT para destruir a "família", que só pode ser a tradicional, além da "homofobia", que se torna um antônimo de termos fantasiosos como "heterofobia" e "cristofobia". Para isso, lançam mão de fake news como o "kit gay", a promoção de um "seminário LGBT infantil”, a distribuição de "mamadeiras eróticas" nas creches brasileiras, a pedofilia como algo do movimento LGBT e tantas outras mentiras que vimos, nos últimos anos, povoar o noticiário nacional. Se lembrarmos das teorizações foucaultianas $(2015 ; 2014)$ sobre a hipótese repressiva e a ordem do discurso, mais do que um silenciamento e proibição da palavra e daquilo que ela compreende, o que está em jogo é, certamente, a disputa pela significação. Sobre essas disputas, bem como sobre a produção dessas fake news em relação a gênero e sexualidade, cabe lembrar ainda que

[...] não foram criadas as devidas dificuldades para aqueles contrários às causas LGBT em um momento crucial, o que pode ter contribuído para abrir, a partir daí, as condições de possibilidade para a emergência de proposições que supúnhamos já terem sido enterradas, como "Ideologia de Gênero", "Escola Sem Partido" etc. Disso tudo até o ápice desse recrudescimento ultraconservador, materializado na eleição de 2018, que elegeu um Presidente da República declaradamente defensor dos discursos fundamentalistas, racistas, homofóbicos/transfóbicos e contra os direitos de minorias, não demorou a tardar. As consequências disso tudo, estamos vivendo agora (SIERRA, 2019: 8). 
No momento em que vivenciamos uma espécie de "normalização" dos discursos de ódio sob a égide da liberdade de expressão, insistimos que, tanto a disputa pelas palavras, quanto pela subjetivação, tem muito a nos dizer sobre a forma de controle dos corpos e dos prazeres dos sujeitos da diversidade que se pretende. Embora haja um retrocesso histórico no que diz respeito à educação para os gêneros e as sexualidades, como o próprio apagamento das discussões sobre gênero e diversidade sexual nos documentos educacionais, além das tentativas de torná-las ilegais, bem como de punir docentes que intentem abarcá-las nos espaços escolares, argumentamos que esse embate não se situa apenas no nível de políticas públicas que se consideravam asseguradas, mas de uma certa promoção das vidas que merecem ser vividas. Nessa percepção, as investidas ultraconservadoras atuariam não só aprofundando a precariedade a que esses sujeitos estão submetidos, mas na decisão daquilo que conta como "vivível" e "não vivível", dificultando o reconhecimento de sujeitos ou grupos específicos que, por isso, estão mais vulneráveis à negligência, à violência e ao extermínio (BUTLER, 2018).

No que concerne à educação e, de modo especial, à educação para os gêneros e as sexualidades, a imposição de um modelo cisheteronormativo, machista, misógino e violento de apreender o mundo em que vivemos coloca em jogo não apenas a urgência de contranarrativas que possam fazer frente aos discursos de ódio e às estratégias ultraconservadoras, mas também a responsabilidade que assumimos, enquanto ativistas e/ ou educadores, de pensar criticamente modos mais justos e compromissados de enfrentamento às desigualdades. A escola, assim, pode ser um dos lugares de onde a crítica emerge, responsabilizando-se, inclusive - diante desse diagnóstico de como os discursos de ódio operam nas disputas narrativas contemporâneas - com estratégias de combate frente a esse empreendimento, que quer sufocar vozes e exterminar corpos dissidentes. Uma educação para os gêneros e sexualidades é fundamental para a criação de novas possibilidades de existir e resistir, de re-existir.

Assim, não nos parece estratégico como forma de enfrentamento que nós, educadoras e educadores, nos apeguemos, quando se fala em gênero e sexualidade na escola, aos projetos de "educação sexual" ancorados em pressupostos exclusivamente biológicos, voltados aos tradicionais temas - reprodução, prevenção da gravidez, infecções sexualmente transmissíveis - todos eles, costumeiramente, trabalhados a partir da norma cisheterossexual. Em uma outra ponta, tampouco cabe a nós, educadoras e educadores, ficarmos apenas espraiando as narrativas de tolerância e respeito à diversidade, na tentativa de deslocar a ênfase puramente biológica que ainda hoje é dada aos gêneros e às sexualidades na escola, uma vez que, mesmo que admitamos tais narrativas como provocadoras de certo deslocamento, elas ainda se mostram, em muitos casos, como um forte dispositivo de regulação que atua banindo para uma zona indigesta os corpos e as experiências que não são tomados como parte dessa generificação chamada 
"diversidade", o que vai sempre incluir alguns, enquanto outros continuarão habitando a zona da exclusão. ${ }^{9}$

Não é à toa, portanto, que os processos de inclusão desses sujeitos na escola aconteçam a partir de mecanismos identitários que classificam, ordenam e hierarquizam, tornando, assim, toda e qualquer experiência escolar passível de decifração. Todavia, este princípio de inclusão aciona, de outro lado, um mecanismo de exclusão da diferença, pois o reconhecimento das identidades sempre deixará de fora os corpos que, de um modo ou de outro, não se ajustam às definições que desenham as fronteiras das identidades. Por isso, mesmo reconhecendo os avanços que a teorização identitária provocou na forma como os sujeitos são encarados, ouvidos e incluídos na esfera social e, por consequência, educacional, é preciso aventar os limites de tal teorização, especialmente no que tange ao esquadrinhamento identitário, que, para operar eficientemente, precisa deixar de fora todos os corpos que não se reconhecem na estabilidade dessa forma de inclusão, pautada em um ideário de respeito e tolerância (SIERRA, DAL'IGNA, 2013: 339).

Em ambos os casos, sejam os apelos à biologia, sejam apenas os apelos às narrativas de respeito e tolerância, o problema permanece o mesmo: não há um questionamento contundente sobre os limites que demarcam a fronteira do que é considerado humano e digno de viver do que não o é. Tensionar esses limites e seus enquadramentos - ou como são forjados nas/pelas relações de poder - talvez seja necessário para que possamos nos situar diante de nós mesmos e do outro, bem como para que possamos ensaiar outras práticas e entendimentos que não estejam descolados do exercício ético e político da apreensão de outros modos de viver os corpos e os prazeres.

\section{Considerações finais}

Ao longo do texto, argumentamos que o modus operandi da disseminação dos discursos de ódio e violência contra as experiências sexuais e de gêneros dissidentes na atualidade tem atravessado um movimento de apropriação dos saberes científico-biológicos e, especificamente, de seus determinismos. Assim, ensaiamos algumas reflexões em torno de três eixos de problematização que se remetem uns aos outros: a invenção de um diferencial (biológico ou "ideológico") entre os sujeitos da norma e os anormais; o estabelecimento de um imaginário sobre a definição de quais corpos podem ocupar a posição de sujeito da "homossexualidade"; e os perigos que cercam a manifestação de um desejo não-heterossexual ou, ainda, de uma performatividade de gênero não cisgênera. 
Entendemos que esses problemas têm sustentado as pautas ultraconservadoras, sendo fundamentais para que suas estratégias funcionem; afinal, os discursos científico-biológicos oferecem uma certa segurança quanto à legitimidade ou veracidade do enunciado, já que ainda desempenham um papel importante nos modos de subjetivação, principalmente, quando associados a outras hegemonias, como a produção midiática, que, inclusive, tem sido um meio eficaz de disseminar os discursos de ódio que intentam conformar o outro à uma mesmidade específica: cisgênera e heterossexual.

Embora nosso gesto tenha sido menos o de contradizer as manifestações ultraconservadoras - já que nem os sujeitos que as proferem estão preocupados com a legitimidade científica daquilo que (re)produzem, mudando suas proposições sempre que necessário - e mais o de questionar as condições de possibilidade para a emergência desses discursos, bem como interrogar a dificuldade que a presença de discursos científicos nos enunciados ultraconservadores representa para os limites da liberdade de expressão, talvez, conhecer criticamente o que diz a própria Biologia possa nos munir de argumentos que constituiriam formas mais justas de nos posicionarmos nesses debates. Mesmo que se possa pensar que fazer isso é jogar o jogo inimigo, uma vez que essas pesquisas e investigações parecem estar sempre a cargo da normalização das sexualidades e gêneros dissidentes, há referenciais teóricos que partem dos próprios conteúdos da Biologia e que ensaiam importantes discussões sobre a construção do que sabemos biologicamente sobre o sexo e o gênero, alinhando-se às perspectivas feministas, filosóficas, históricas e sociológicas, como Anne Fausto-Sterling, Elsa Dorlin, Ilana Lowy e Londa Schiebinger. Colocar a Biologia sob suspeita pode, afinal, ressignificar modos de existência descritos pela fisiologia, pela genética e, talvez, pela evolução. Pode, é certo, nos provocar a pensar de outras maneiras as formas pelas quais vivemos nossos prazeres e, quem sabe, afrouxar as amarras que por tanto tempo nos disseram: anormais.

Além disso, uma leitura performativa dos discursos de ódio pode nos ajudar a situar as estratégias ultraconservadoras de um modo mais objetivo, para além da polêmica, por assim dizer, já que nos permite um outro olhar para a produção de enquadramentos ou operações políticas que forjam as normas de inteligibilidade à possibilidade de uma vida mais vivível para os sujeitos que experienciam um sexo e/ou um gênero dissidente. A partir das teorizações de Judith Butler (2019, p. 37), acreditamos que esse outro olhar poderia ser "um ato de fazer um balanço de nosso mundo e participar de sua transformação social", já que nessa mesma balança está a nossa capacidade de sentir e apreender e, de certo modo, a possibilidade de articular "desenquadramentos" (BUTLER, 2015) ou deslocamentos críticos em relação às perspectivas cisheteronormativas de entender outros modos de vida - inclusive, na escola. 


\section{Notas}

1 Este artigo apresenta, de forma revista e ampliada, resultados da dissertação de mestrado intitulada "Ciência, Fundamentalismo religioso e Diversidade. A apropriação de discursos científicos-biológicos para a produção de ódio e violência contra as sexualidades e gêneros dissidentes nas mídias sociais", defendida em março de 2018, no Programa de Pós-Graduação em Educação da Universidade Federal do Paraná, que investiga como os discursos científico-biológicos têm sido apropriados pelo fundamentalismo religioso nas mídias sociais para a produção de violência e exclusão das experiências sexuais e de gêneros dissidentes.

2 A heteronormatividade pode ser entendida como "[...] uma denominação contemporânea para o dispositivo histórico da sexualidade que evidencia seu objetivo: formar a todos para serem heterossexuais ou organizarem suas vidas a partir do modelo supostamente coerente, superior e 'natural' da heterossexualidade." (MISKOLCI, 2009:156-157). Associamos o prefixo "cis" a este conceito porque entendemos que o corpo requerido para o funcionamento do sistema corpo-gênero-desejo é o cisgênero, ou seja, aquele cujo gênero é considerado coerente em relação ao sexo designado e imposto pelos saberes médicos e científicos.

3 Parte dos materiais empíricos aqui discutidos são de um conjunto maior de materiais presentificados na pesquisa que originou este texto e que incluem, além dos tweets e dos artigos científicos, alguns recortes de notícias. Justificamos também que não traremos, aqui, os nomes, ou a quem pertence os perfis do Twitter que foram analisados, porque não se trata de uma "caça às bruxas", tampouco simplificar a análise com o entendimento de que esses sujeitos sejam soberanos, fonte do discurso, a origem do que enunciam ou, ainda, os únicos responsáveis pela disseminação de discursos de ódio no Brasil. Evidente que importa a posição de sujeito ocupada no discurso, inclusive porque são pessoas públicas com grande histórico de disseminação de fake news e discursos de ódio na internet, mas entendemos que esses perfis são apenas parte de uma rede discursiva maior, da qual emerge o cenário conservador na atualidade.

4 Referência ao artigo Gender: a useful category of historical analysis, de Joan Scott.

5 É importante ressaltar que quando os documentos científicos usam o termo "homossexual" é provável que não estejam falando exclusivamente de experiências sexuais e/ou afetivas entre homens. Há, sem dúvida, um maior interesse nesses sujeitos, mas isso não significa que outras experiências não tenham sido capturadas; não à toa encontramos nesses documentos alguns excertos de caráter confessional, tomados dos sujeitos examinados, que os aproximam de experiências trans, por exemplo. Igualmente, o ultraconservadorismo toma a "homossexualidade" como um guarda-chuva para outras experiências dissidentes, isso quando elas não são remetidas a termos como "homossexualismo". Para uma discussão ampliada ver: Pereira, 2018.

6 Para essa discussão detalhada ver: Pereira, 2018.

7 Esse estudo tem sido amplamente citado como prova incontestável da funcionalidade das terapias de reorientação sexual, até porque o autor, Robert Spitzer, presidiu a comissão de revisão do DSM-III, o que, em teoria, faria com que o estudo não fosse interessado.

8 Interpretação ultraconservadora do inciso VI do art. $5^{\circ}$ da Constituição que tem servido como mote aos partidários do Escola sem Partido.

9 Aliás, pode-se considerar que até mesmo essas abordagens estão ameaçadas, já que não há mais sequer a outrora parceria entre Estado e movimentos sociais que viabilizava esse modo de in/exclusão a partir de uma lógica identitária (SIERRA, 2013).

\section{Referências}

BUTLER, Judith. Lenguaje, poder e identidad. Tradução de Javier Sáez e Beatriz Preciado. Madrid: Editorial Síntesis, 1997. 
. Corpos em aliança e a política das ruas. Notas para uma teoria performativa de assembleia. Rio de Janeiro: Civilização Brasileira, 2018. 2003.

Problemas de gênero: feminismo e subversão da identidade. Rio de Janeiro: Civilização Brasileira,

. “Critically queer". GLQ: a journal of lesbian \& gay studies, Durhan, v. 1, p. 17-32, 1993.

. Vida precaria. El poder del duelo y la violência. Tradução de Fermín Rodríguez. Buenos Aires: Paidós, 2006.

Quadros de guerra. Quando a vida é passível de luto? Tradução de Sérgio Tadeu de Niemeyer Lamarão e Arnaldo Marques da Cunha; revisão de tradução de Marina Vargas; revisão técnica de Carla Rodrigues. 1ª ed. Rio de Janeiro: Civilização Brasileira, 2015.

. Vida precária. Os poderes do luto e da violência. Belo Horizonte: Autêntica, 2019.

CÉSAR, Maria Rita de Assis; DUARTE, André de Macedo. “Governamento e pânico moral: corpo, gênero e diversidade sexual em tempos sombrios". Educar em Revista, Curitiba, v. 33, n. 66, p. 141-155, out./dez., 2017.

CURITIBA. Prefeitura Municipal. LEI no 14681 DE 2015. Aprova o Plano Municipal de Educação - PME, da cidade de Curitiba. Disponível em: <https://goo.gl/d8AYCq>. Acesso em jan. 2018.

DORLIN, Elsa. Séxo, género y sexualidades. Introducción a la teoria feminista. Tradução de Victor Goldstein. Buenos Aires: Nueva Visión, 2009.

FAUSTO-STERLING, Anne. "The five sexes. Why male and female are not enough". The Sciences, Nova Iorque, p. 20-25, mar./abr. de 1993.

. Sex/Gender: biology in a social world. New York and London: Routledge, 2012.

Sexing the body: gender politics and the construction of sexuality. New York: Basic Books, 2000.

FISCHER, Rosa Maria Bueno. “O estatuto pedagógico da mídia: questões de análise”. Educação e Realidade, Porto Alegre, v. 22, n. 2, p. 59-80, jul./dez. de 1997.

FOUCAULT, Michel. História da sexualidade I: A vontade de saber. Rio de Janeiro: Paz e Terra, 2015.

A ordem do discurso. São Paulo: Edições Loyola, 2014.

LOPES, Maura Corcini. “Inclusão como prática política de governamentalidade". In: LOPES, Maura Corcini; HATTGE, Morgana Domênica. Inclusão Escolar: conjunto de práticas que governam. Belo Horizonte: Autêntica. p.107-130, 2009.

MACCULLOCH, Malcolm. "Biological aspects of homosexuality". Journal of Medical Ethics, Londres, v. 6, n. 3, p. 133-138, set., 1980.

MISKOLCI, Richard. “A Teoria Queer e a Sociologia: o desafio de uma analítica da normalização". Sociologias, Porto Alegre, v. 11, n. 21, p. 150-182, jan.jun., 2009.

. "Pânicos morais e controle social - reflexões sobre o casamento gay". Cadernos Pagu, Campinas, n. 28, p. 101-128, jan.jjul.,2007.

NATIVIDADE, Marcelo. "Homossexualidade, gênero e cura em perspectivas pastorais evangélicas".

Revista Brasileira de Ciências Sociais, São Paulo, v. 21, n. 61, p. 115-132, jun., 2006. 
OWENSBY, Newdigate M. "Homosexuality and lesbianism treated with metrazol". Journal of Nervous \& Mental Disease, Filadélfia, v. 92, n. 1, p. 65-66, jul., 1940.

PELUCIO, Larissa; MISKOLCI, Richard. "A prevenção do desvio: o dispositivo da aids e a repatologização das sexualidades dissidentes". Sexualidad, Salud y Sociedad, Rio de Janeiro, n. 1, p.125$157,2009$.

PEREIRA, Tamires Tolomeotti. Ciência, Fundamentalismo religioso e Diversidade. A apropriação de discursos científicos-biológicos para a produção de ódio e violência contra as sexualidades e gêneros dissidentes nas mídias sociais. Dissertação de mestrado. Universidade Federal do Paraná, Curitiba, 2018.

RIBEIRO, Leonídio. "Ciência, homossexualismo e endocrinologia". Revista Latinoamericana de Psicopatologia fundamental. São Paulo, v. 13, n. 3, p. 498-511, set., 2010.

SIERRA, Jamil Cabral. Homossexuais, insubmissos e alteridades em transe. Representações da homocultura na mídia e a diferença no jogo dos dispositivos contemporâneos de normalização. Dissertação de mestrado. Universidade Estadual de Maringá, Maringá, 2004.

. "Corpo, sexualidade e poder: a homossexualidade na mídia e as biopolíticas de prevenção contra a AIDS". Textura, Canoas, v. 15, n. 28, p.111-128, mai./ago.,2013.

. "Identidade e diversidade no contexto brasileiro: uma análise da parceria entre Estado e movimentos sociais LGBT de 2002 a 2015". Revista Anos 90, Porto Alegre, v. 26, p.1-14,2019.

SIERRA, Jamil Cabral; DAL'IGNA, Maria Cláudia. Parceria e governamentalidade: ferramentas para problematizar as relações socioeducacionais contemporâneas. Educação Unisinos, São Leopoldo, v. 3, n. 22, p.332-340, jul./set, 2013.

SILVERMAN, Daniel; ROSANOFF, William R. “Electroencephalographic and neurologic studies of homosexuals". The Journal of Nervous and Mental Disease, Filadélfia, v. 101, n. 4, p. 311-321, abr.,1945.

SPITZER, Robert L. "Can some gay men and lesbians change their sexual orientation? 200 Participants reporting a change from homosexual to heterosexual orientation". Archives of sexual behavior, Basiléia, v, 32, n.5, p. 403-417, out.,2003.

TREVISAN, João Silvério. Devassos no paraíso. A homossexualidade no Brasil, da colônia à atualidade. Rio de Janeiro: Record, 2002.

WILLIAMS, Edwin G. "Homosexuality: a biological anomaly”. Journal of Nervous \& Mental Disease, Filadélfia, v. 99, n. 1, p. 65-70, jan.,1994. 